\title{
Microstructure-dependent densification of polar firn derived from X-ray microtomography
}

\author{
Johannes FREITAG, Frank WILHELMS, Sepp KIPFSTUHL \\ Alfred Wegener Institute for Polar and Marine Research, P.O. Box 120161, D-27515 Bremerhaven, Germany \\ E-mail:jfreitag@awi-bremerhaven.de
}

\begin{abstract}
The densification of dry polar snow and firn results in a continuous increase of density with depth accompanied by significant density fluctuations within seasonal layers. Density measurements of high spatial resolution reveal a persistent minimum of density fluctuations in the vicinity of the snow-firn transition $\left(0.55-0.65 \mathrm{~g} \mathrm{~cm}^{-3}\right)$ in firn-core records. In this study we give an explanation for the fluctuation minimum by applying a new method of X-ray microtomography to obtain three-dimensional (3-D) structural data of a Greenland firn core. At 13 different depths between 10 and $78 \mathrm{~m}$ a set of 16 samples of $40 \mathrm{~cm}$ total length for each depth interval was measured. A reconstructed firn segment of $40 \mathrm{~cm}$ covers 1-2 years of snow accumulation. Using digital image analysis techniques, different structural parameters are estimated including 3-D pore and particle sizes and specific surface areas. It is shown that the densification rates of snow and firn layers consisting of coarse particles are much higher than those consisting of fine particles within the same depth interval. This causes a density crossing of fine- and coarse-grained layers with a minimum of density variations at the crossover point. This crossing-over implies that formerly dense layers in the seasonal density signal are not of the same origin as dense layers in the deeper part of the firn column and that the seasonal density signal will totally change shape with depth. It is speculated that in coarse- and fine-grained firn the dominant mechanism of densification acts over different regimes of density.
\end{abstract}

\section{INTRODUCTION}

Structural properties of the initial particle compositions including initial size, shape and density crucially affect the process of sintering, as is observed for many materials in ceramic science (German, 1996). Until now, little attention has been paid to this aspect in relation to the densification processes of polar snow and firn. However, the structural variability in snow and firn is immense. The well-known stratigraphic layering in firn is caused by seasonal, diurnal or even faster changes of wind, air pressure, temperature, solar radiation and other atmospheric parameters during snowfall events or afterwards. A common feature is the persistent minimum of density fluctuations in the vicinity of the snow-firn transition (Gerland and others, 1999; Wilhelms, unpublished data; this study).

Previous densification models have dealt with mean density profiles, ignoring the seasonal variability in snow and firn layers (Maeno and Ebinuma, 1983; Ebinuma and Maeno, 1987; Wilkinson, 1988; Arnaud and others, 1998, 2000). The densification of polar snow and firn is understood as a process of pressure sintering driven by the overburden ice load and the surface free energy of the porous ice matrix. The densification process has been divided into three stages by two critical densities. The critical values indicate densities at which the rate of densification decreases significantly due to a change in dominant densification mechanism. During the initial stage the snow deposits are mainly compacted by mechanical destruction and rearrangements of grains due to grain-boundary sliding (Alley, 1987a) up to the first critical density of $0.55 \mathrm{~g} \mathrm{~cm}^{-3}$ (equal to a porosity of about 0.4). The concept of critical density at around $0.55 \mathrm{~g} \mathrm{~cm}^{-3}$ was first used by Anderson and Benson (1963). According to Anderson and Benson (1963), the critical density of $0.55 \mathrm{~g} \mathrm{~cm}^{-3}$ corresponds closely with the maximum packing densities that can be attained with uniformly sized granular aggregates. However, Gow (1968) observed that intergranular bonding is well developed in snow aggregates with densities $<0.55 \mathrm{~g} \mathrm{~cm}^{-3}$. Such bond growth at shallow depths should inhibit any approach to a simply mechanically packed aggregate at the critical density. The intermediate stage is dominated by plastic deformation with a power-law creep (Maeno and Ebinuma, 1983) until the second critical density of $0.82-0.84$ (equal to porosities of 0.11 and 0.08 ), where the pore space separates into isolated air bubbles. During the final stage, the air bubbles are further shrunk until the density of bubble-free ice $\left(0.919 \mathrm{~g} \mathrm{~cm}^{-3}\right.$ at $\left.-25^{\circ} \mathrm{G}\right)$ is attained. An additional critical density of $0.730 \mathrm{~g} \mathrm{~cm}^{-3}$ (equal to porosity 0.2 ) is suggested by Ebinuma and Maeno (1987): at this density the grain rearrangement is completed and the contact area between ice particles should become maximum.

A microscopical approach for a geometrical model of pressure sintering was introduced by Arzt (1982) and applied to the densification of Antarctic firn by Arnaud and others (2000). It is based on pressure-sintering processes of monosized spheres with adjusted initial densities for the intermediate state, assuming that aggregates of particles satisfy the requirement of zero contact areas at that density. A more detailed understanding of firn densification would improve the interpretation of the climate record stored in polar ice cores. Density variations at the firn-ice transition 


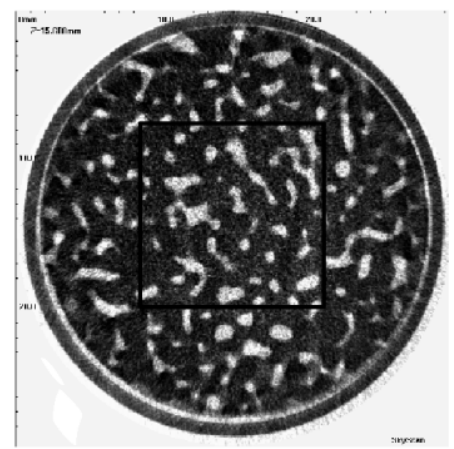

a
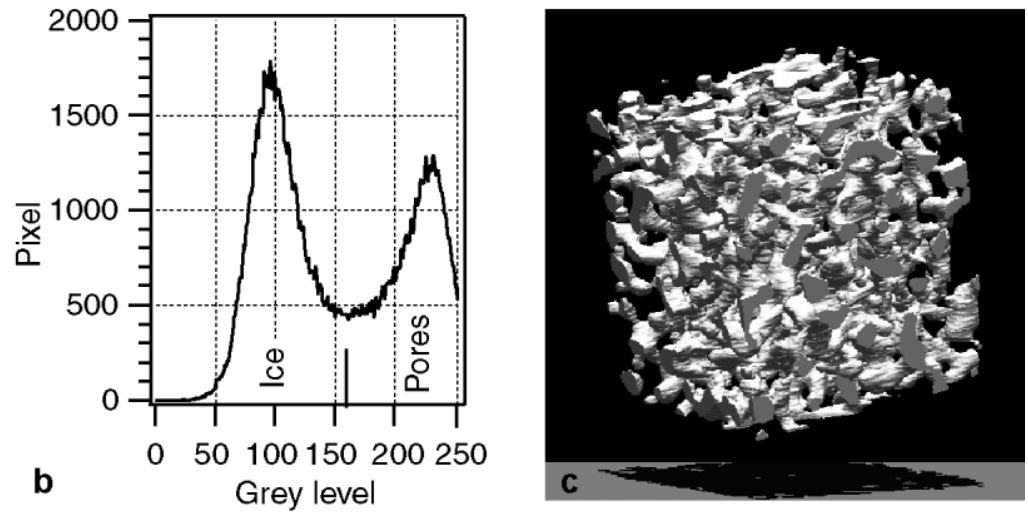

Fig. 1. (a) Reconstructed horizontal cross-section through a cylindrical firn sample B26_51_1 from $51 \mathrm{~m}$ depth in raw data format. The pores appear in bright and the ice matrix in dark grey values. The outlined square indicates the $12 \mathrm{~mm} \times 12 \mathrm{~mm}$ area of interest for analytical processing. Notice the blurred pore areas close to the margin caused by the filling with fine snow after drilling. (b) Typical grey-level histogram of a single cross-section. (c) Binarized firn cube of B26_51_l. It is $12 \times 12 \times 12 \mathrm{~mm}^{3}$ in size and built from a stack of 300 segmented images. The pore space is coloured in white, whereas the ice matrix is transparent.

are a source of uncertainty in the estimation of gas ages and age distributions in isolated gas bubbles, which are crucial for dating the gas content (Stauffer and others, 1985).

Several studies have investigated the structural properties of polar firn and snow mainly based on estimates from two-dimensional (2-D) thin sections (Gow, 1975; Alley and others, 1982, Alley, 1987b; Arnaud and others, 1998). They focus on the evolution of mean values during densification. Only Alley and others (1982) separate fine- and coarsegrained firn in a study of an Antarctic firn core and speculate about different mechanisms which may control the densification process in fine and coarse firn. Estimates from three-dimensional (3-D) reconstructions by means of $\mathrm{X}$ ray computer tomography (XCT) have been relatively recent. Lundy and others (2002) have measured snow density by XCT using a probe chamber cooled by dry ice which demonstrates the capabilities of the technique.

In this study, we present high-resolution profiles of structural data from an $80 \mathrm{~m}$ long firn core to investigate the influence of structure on densification. A method of XCT operating in a cold room was developed which allows a suitable processing of more than 200 cube-shaped samples of polar firn covering the whole range of seasonal variations along the core. From the 3-D reconstructions the specific surface areas, pore and ice particle sizes are derived. It will be shown that the densification depends on particle size and explains the observed characteristic minimum of density fluctuations in the density profiles of polar firn. All measurements were carried out on samples of the firn core B26, retrieved during the North Greenland traverse of the Alfred Wegener Institute in 1995 (Schwager, 2000). The borehole was located at $77^{\circ} 15^{\prime} \mathrm{N}, 49^{\circ} 13^{\prime} \mathrm{W}$. The mean accumulation rate was $0.180 \mathrm{~m}$ w.e. $\mathrm{a}^{-1}$. The mean firn temperature was $-30.6^{\circ} \mathrm{C}$.

\section{X-RAY TOMOGRAPHY ON POLAR FIRN}

The pore structures of snow and firn specimens were measured at $-25^{\circ} \mathrm{C}$ by XCT using a portable Micro-CT scanner (1074SR SkyScan) inside a cold room. All the grease of the movable parts was replaced with a cold-temperature grease (ISOFLEX TOPAS L32, Klüber company). The CT scanner works with an integrated microfocus X-ray tube which runs at $40 \mathrm{KV}$ with a current intensity of $1000 \mu \mathrm{A}$. A charge-coupled device (CCD) camera of $768 \times 512$ pixels and 256 grey levels is used as an X-ray detector. The object is placed on a movable turntable between source and detector. During the scanning procedure the object rotates at intervals of $0.9^{\circ}$. A set of 210 shadow images is captured while the rotation completes a semicircle. A digital convolution algorithm with back-projections for fan beams transforms these shadow images into a series of horizontal crosssection images which represent the 3-D structure of the object based on local differences in X-ray absorption (Skyscan 1074 instruction manual, 2002, http://www.skyscan.be). The pixel resolution of the reconstructed grey-level images is $40 \mu \mathrm{m}$. The distance between adjacent reconstructed images is also $40 \mu \mathrm{m}$. Therefore the reconstructed object is represented by a 3 -D grid of grey values (voxels) with a spacing of $40 \mu \mathrm{m}$ in $x, y$ and $z$ directions. In analogy to the term pixel used in the 2-D case, a voxel is defined as the smallest distinguishable box-shaped part of a 3-D space. The maximum specimen size for reconstruction is limited to cylinders $29 \mathrm{~mm}$ in diameter and $20.4 \mathrm{~mm}$ in height. However, for digital image analysis only a cubic region of $12 \mathrm{~mm}$ side length is chosen, which minimizes the processing to $300 \times 300 \times 300$ voxels. The area of interest is located in the interior of the reconstructed object to restrict data analysis to pore-structure areas which are not disturbed by sample preparation. The cylindrical snow and firn specimens are drilled out of the main core with a hole saw.

As a first step in digital analysis, a median filter of a mask of $3 \times 3$ voxels is applied to the images. The filter replaces the grey level of each voxel by the median of the grey levels in the neighborhood of that voxel and reduces noise patterns with spike-like components, as can be seen in the raw dataset of the reconstructed cross-section images (Fig. la). In a second step, the images are separated in voxels representing solid ice or air-filled voids by applying a single global threshold value to the bimodal grey-level histograms. Due to the large differences in X-ray absorption between air and ice, the mean grey levels of ice and void representing voxels differ by as much as 100 units, which leads to a clear separation in spite of the rather simple segmentation method. As the global threshold, a grey value of about 160 is taken which is the mean of the two clearly identifiable 
maxima in the bimodal grey-level histograms. The 300 binarized images are pooled to estimate the porosity, density, specific surface area, pore and ice-cluster size distribution functions.

The porosity $n$ is given as the ratio of void representing voxels to the total voxel number of the considered firn cube. The density $\rho$ is derived from porosity $n$ with the approximation

$$
\rho=(n-1) \rho_{\text {ice }}
$$

with a density of bubble-free ice $\rho_{\text {ice }}=0.919 \mathrm{~g} \mathrm{~cm}^{-3}$ at $-25^{\circ} \mathrm{C}$.

The specific surface area $A_{\text {spec }}$ is defined as the surface of the pores inside the firn cube divided by the cube volume. $A_{\text {spec }}$ is derived by counting the faces of the pore voxels which lie at the borders of the ice voxels in the cubic matrix grid. The number of faces is multiplied by a single face area of a cubic voxel which is equal to $1600 \mu \mathrm{m}^{2}$, and afterwards divided by the total volume of the firn cube.

The pore and ice-cluster size distribution functions are derived from 3-D opening-size distributions first introduced by Serra (1982) in mathematical morphology. An opening operation is defined as an erosion filter followed by a dilation. For the analysis of ice clusters and pores we used the opening with spherical structuring elements of different diameter, ignoring the distinction between pore bodies and throats as well as the grain boundaries of the ice matrix. Instead, the pore space is divided into a set of spherical pores of different diameter. Hereafter, a pore voxel at any point within the pore space contributes to that size fraction that is given by the largest sphere which includes this point and which fits totally into the pore space. In the context of the ice phase, we introduce the term ice-cluster size instead of using the well-defined terms crystal size or grain-size, because the derived ice spheres could represent a part or a set of crystals. However, comparison measurements will show that the sphere is a good representation of a single ice grain in Greenland polar firn.

The openings are performed on the 3-D voxel matrix following the implementation by Vogel (1997). The openings are calculated for both the pore and ice phase, using spherical structuring elements of increasing diameter. After each opening, the volume densities of the selected phases are obtained from the proportion of the remaining voxels. The volume densities represent pores or ice clusters that are larger than spheres with the diameter of the related structuring element. From the volume density data, the size distributions are derived by differentiation. The mean values of the pore $\left(d_{\text {pore }}\right)$ and ice-cluster diameters $\left(d_{\text {ice }}\right)$ are volume weighted.

The structural properties are calculated from 208 reconstructed firn samples of B26. The samples are taken from 13 different depth intervals of $40 \mathrm{~cm}$ length beginning at depths of 10.18, 12.76, 13.60, 14.38, 15.68, 18.66, 23.00, 27.61, $32.00,40.00,51.40,66.36$ and $78.31 \mathrm{~m}$. They are picked from depths where the density profile measured by gamma absorption shows a typical cycle over the whole range of small-scale variation. For each depth interval, approximately 16 firn cubes $12 \mathrm{~mm}$ on a side are measured. Based on the mean accumulation rate of $0.180 \mathrm{~m}$ w.e. $\mathrm{a}^{-1}$, the 16 firn cubes of each depth interval cover the accumulation of about 1 year in the upper part $(10-20 \mathrm{~m})$ and up to 2 years in the lower part of the firn core $(40-80 \mathrm{~m})$. Since a single firn cube of $12 \mathrm{~mm}$ side length consists of about ten ice crystal layers, this is equivalent to 1000 crystals per cube volume.
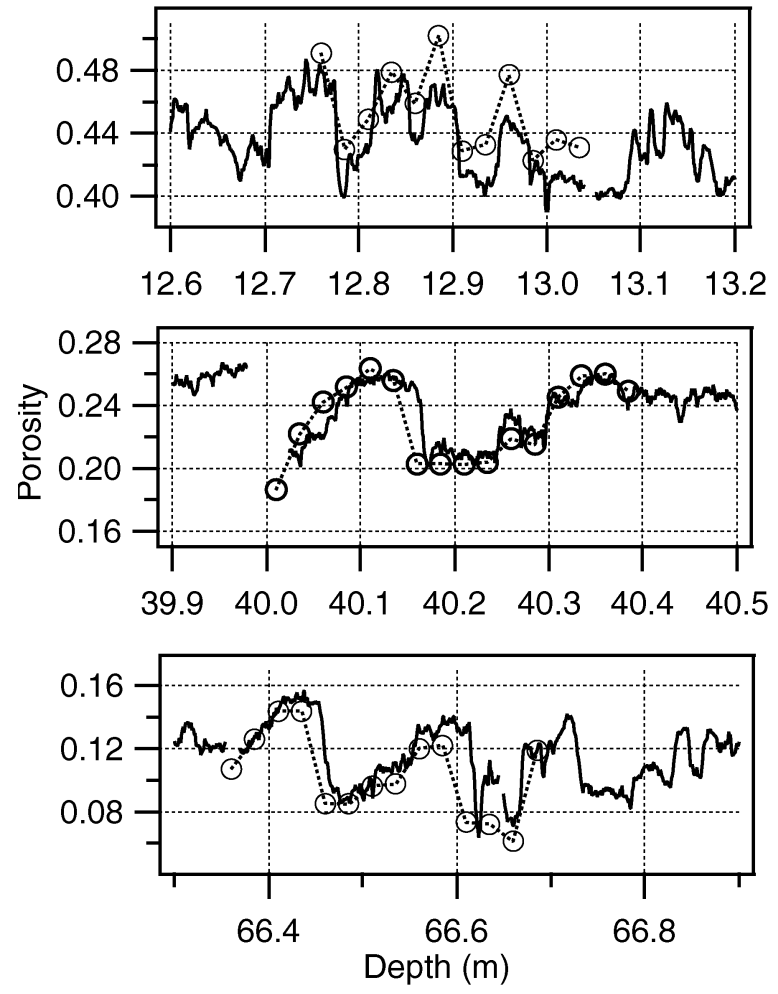

Fig. 2. Gamma porosity (solid lines) in comparison to the porosity values measured by XCT (circles connected with dotted lines) for different depth intervals. The porosities of XCT are averaged over $12 \mathrm{~mm}$ depth intervals.

\section{COMPARISON TO GAMMA-ABSORPTION AND OPTICAL METHODS}

To evaluate the precision of the XCT method, the density of B26 is independently measured by a non-destructive gamma-absorption method. Details of the absorption method are given by Wilhelms (1996). The density is horizontally averaged over the entire circular cross-section of the firn core which is approximately $100 \mathrm{~mm}$ in diameter and measured with a vertical resolution of $2 \mathrm{~mm}$ (Fig. 2). For comparison, the density is converted to porosity $n$ using Equation (1). Figure 2 displays $n$ measured by both gamma absorption and XCT in different depth intervals. The $\mathrm{XCT}$-porosity values are averaged over the volume of the firn cubes of $12 \mathrm{~mm}$ side lengths. The porosity values measured by the two independent methods are in excellent agreement with each other in the porosity range $0.2-0.3$ or at $40 \mathrm{~m}$ depth, respectively, where the deviations are $<1 \%$. However, for porous firn $(n>0.4)$ the XCT method shows slightly higher porosities than the gamma-absorption method. In high compacted firn $(n<0.2)$ the gamma absorption method produces higher values.

Another, more qualitative verification of the non-destructive XCT method is performed on a selected firn cube B26_66.4 from $66 \mathrm{~m}$ depth using the optical serial sectioning method (OSM) described in Freitag and others (2002). Identified cross-sections measured by XCT are compared to surface sections of the same firn cube after it is cut and recorded by a CCD camera which is sensitive in the visible range. The porosities derived from XCT and OSM for the same surface sections are in good agreement, with deviations $<5 \%$. In a sensitivity test, the threshold of the XCT images is varied by 20 units and leads either to artificial ice 


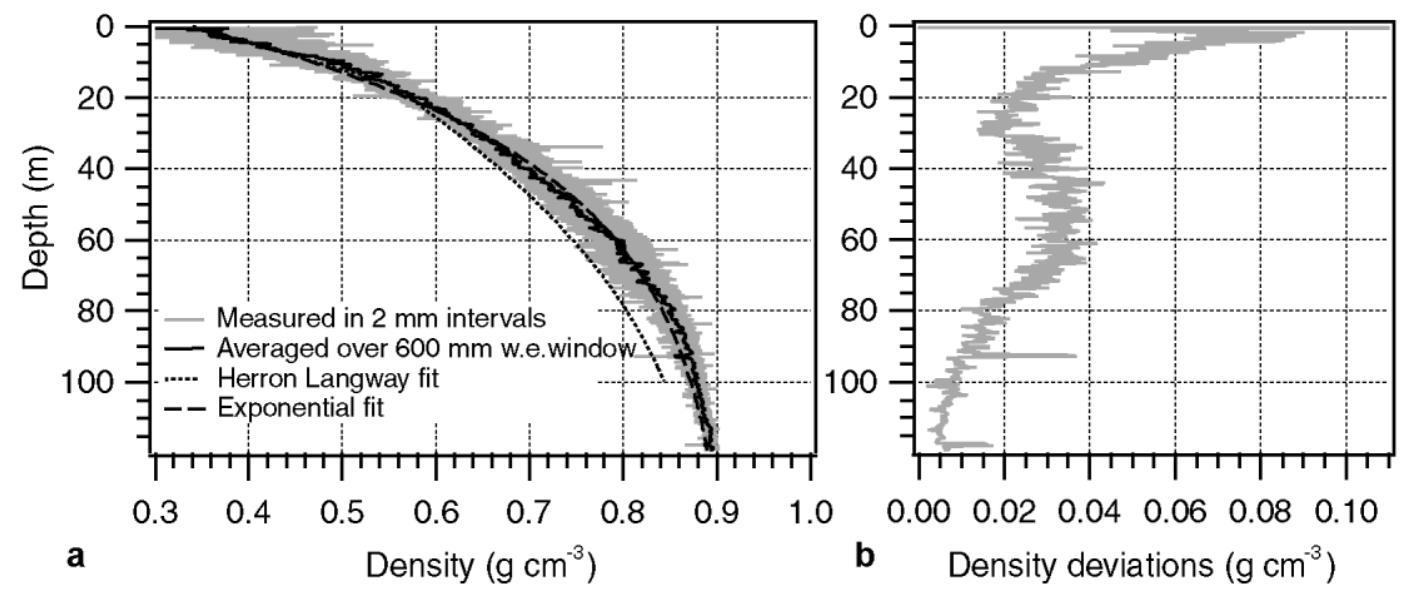

Fig. 3. (a) Highly resolved density profile of firn core B26 measured by gamma absorption. Additionally, the running mean over a $600 \mathrm{~mm}$ w.e. window and two model curves are plotted using the Herron and Langway (1980) approximation and an exponential fit. (b) Density fluctuations with depth indicated by the twofold standard deviation of the running mean in a 600 mm w.e. window. Notice the distinct minimum between 20 and $30 \mathrm{~m}$.

islands inside of pores or to an expansion of pore areas into locations where the optical method has identified the ice matrix. Thus, the test confirms the value of the global threshold as the mean of the two local maxima in the bimodal grey-level histograms even in the qualitative sense of geometrical similarity.

The reproducibility of the XCT measurements is investigated by scanning the same firn cubes with a delay of 3 months, which was approximately the time-span for the whole laboratory campaign. The deviations in porosity and specific surface area are around $2 \%$, low enough to detect the smallest changes during the densification of polar firn with this method.

\section{RESULTS}

The high-resolution density profile of the Greenland firn core B26 is measured at $2 \mathrm{~mm}$ intervals by gamma absorption and shown in Figure 3. The data are averaged with a running mean of $600 \mathrm{~mm}$ w.e. which is about the snow accumulation of 3 years. The mean density $\left(\right.$ in $\mathrm{g} \mathrm{cm}^{-3}$ ) follows an empirical fit given as

$$
\rho(z)=0.918-0.58 \mathrm{e}^{-0.025 z},
$$

where $z$ is the depth in meters. An approximation with the empirical formula of Herron and Langway (1980), taking into account the firn temperature of $-30.6^{\circ} \mathrm{C}$ and accumulation rate of $0.180 \mathrm{mw}$.e. $\mathrm{a}^{-1}$ at $\mathrm{B} 26$, underestimates the mean densification with depth (Fig. 3a, dotted curve). In the lower part of the firn core the measured densities are up to $8 \%$ higher than is predicted by the Herron and Langway approximation.

The small-scale fluctuations are illustrated in Figure 3b where the two-fold standard deviation from the running mean over a $600 \mathrm{~mm}$ w.e. window is plotted. Per definition $95 \%$ of the data are in that range. Beginning with values of $0.08 \mathrm{~g} \mathrm{~cm}^{-3}$ in the uppermost meters, the fluctuations decrease to a minimum of $0.02 \mathrm{~g} \mathrm{~cm}^{-3}$ in the range $20-30 \mathrm{~m}$ $\left(0.55-0.65 \mathrm{~g} \mathrm{~cm}^{-3}\right)$. However, between 30 and $40 \mathrm{~m}$ the fluctuations increase to $0.04 \mathrm{~g} \mathrm{~cm}^{-3}$. Below $65 \mathrm{~m}$ the fluctuations decrease.

The firn structure measured by XCT on single cubes shows ice-cluster and pore size distributions unimodal in shape (Fig. 4). The distributions representing a firn layer
$12 \mathrm{~mm}$ thick can be best fitted by Gaussian distribution functions. The widths of the pore size distribution functions $\sigma_{\text {pore }}$ (as defined in the Gaussian function) decrease continuously from $0.41 \pm 0.09 \mathrm{~mm}$ at $10 \mathrm{~m}$ depth to $0.31 \pm 0.03 \mathrm{~mm}$ at $78 \mathrm{~m}$ depth. The widths are approximately $50 \%$ of the mean pore diameters. For the ice clusters the widths $\sigma_{\text {ice }}$ vary only slightly with depth, between $0.30 \pm 0.04$ and $0.35 \pm 0.03 \mathrm{~mm}$. The relative widths to the mean ice-cluster diameter decrease from $40 \%$ at $10 \mathrm{~m}$ depth to $20 \%$ at $78 \mathrm{~m}$ depth. Figure 5 displays two seasonal profiles from different depth intervals. The profile from $15 \mathrm{~m}$ depth covers approximately 1 year of snow accumulation; the profile from $51 \mathrm{~m}$ depth with more compacted snow reflects 2 years rather than 1 year. Within seasonal cycles the mean values of the firn layers show one to three local minima or maxima, sometimes with abrupt changes on the scale of centimeters.

At $15 \mathrm{~m}$ depth, the mean ice-cluster diameter $d_{\text {ice, }}$, the mean pore diameter $d_{\text {pore }}$ and the porosity $n$ are positively correlated over the seasonal cycle. The specific surface area $A_{\text {spec }}$ shows a clear anticorrelation to the former parameters. Such behavior corresponds to the general observation that fine-grained snow is denser and has more free surfaces than coarse-grained snow. However, these relations seem to change with depth. As indicated by the profile at $51 \mathrm{~m} \mathrm{depth}$,

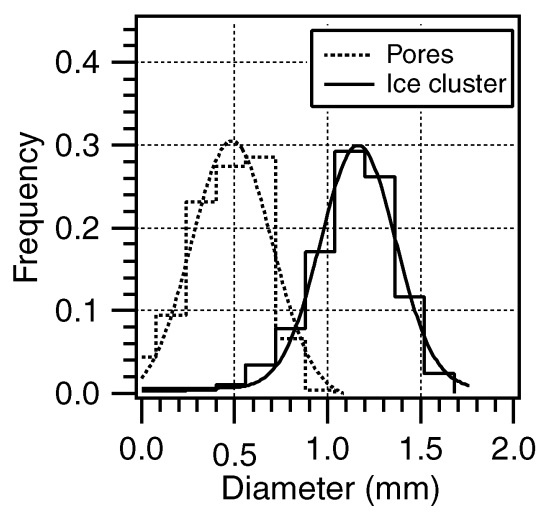

Fig. 4. Example of a pore (dotted lines) and ice-cluster (solid lines) size distribution fitted by Gauss functions. The estimations are performed on a reconstructed firn cube from the depth interval $51.260-51.272 \mathrm{~m}$. 


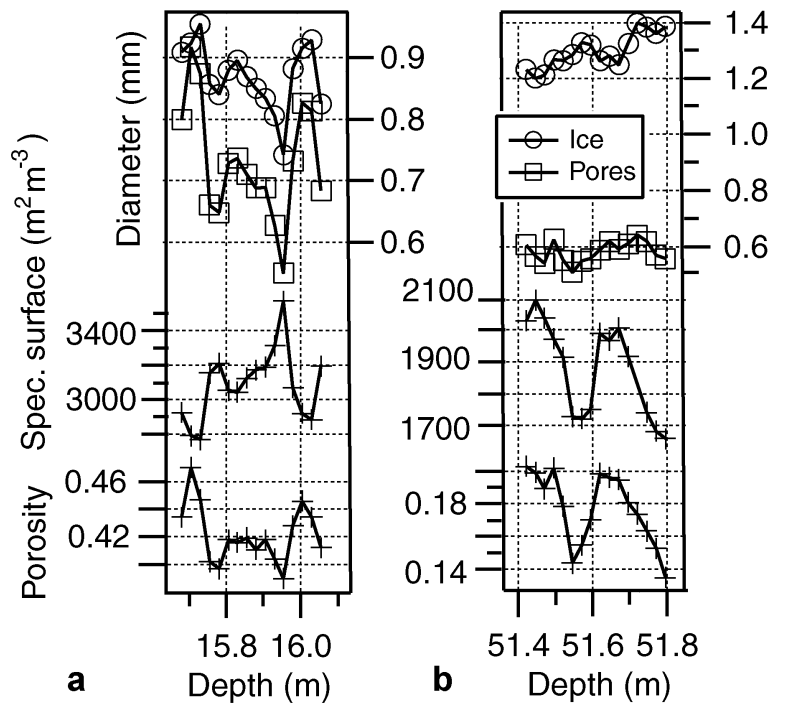

Fig. 5. Profiles of ice-cluster diameter $d_{\text {ice }}$ (circles), pore diameter $d_{\text {pore }}$ (squares), specific surface area $A_{\text {spec }}$ (crosses) and porosity $n$ (crosses, below) over firn intervals of $40 \mathrm{~cm}$ length at $15 \mathrm{~m} \mathrm{(a)}$ and $51 \mathrm{~m}(\mathrm{~b})$ depth.

$d_{\text {ice }}$ increases when $n$ decreases and vice versa, which is almost opposite to the behavior occurring at depths above $15 \mathrm{~m}$. At $51 \mathrm{~m}$ depth, $d_{\text {pore }}$ shows no clear correlation to the other parameters, and $A_{\text {spec }}$ is positively correlated to porosity $n$.

The change in the seasonal dependencies becomes obvious by considering their evolutions along the whole firn column. In Figure 6 , all data of $A_{\text {spec }}, d_{\text {ice }}$ and $d_{\text {pore }}$ are plotted against $n$. In the porosity range $0.35<n<0.55$, $A_{\text {spec }}(n)$ decreases within seasonal cycles with a mean slope of $-8400 \mathrm{~m}^{2} \mathrm{~m}^{-3}$ in the linear regression curves. For $0.2<n<0.35, A_{\text {spec }}(n)$ shows a different behavior, with higher data scattering and slopes of approximately zero over a seasonal cycle. For $n<0.2, A_{\text {spec }}(n)$ shows an opposite trend, with a positive slope of $6700 \mathrm{~m}^{2} \mathrm{~m}^{-3}$ in the regression curves. The same changes in the seasonal dependencies also appear for the ice-cluster sizes: for $n<0.2, d_{\text {ice }}$ decreases with $n$ following a slope of $-3.3 \mathrm{~mm}$ within seasonal cycles. For $0.2<n<0.35$, the slope becomes $-0.3 \mathrm{~mm}$ and switches to positive values of up to $2 \mathrm{~mm}$ in the range $n>0.35$. The pore sizes $d_{\text {pore }}$ and $n$ are positively correlated within all seasonal cycles. The slopes of the regression curves decrease from $3.8 \mathrm{~mm}$ in the porosity range $n>0.35$ to $1.5 \mathrm{~mm}$ for $n<0.2$.

In general, a densification from $n=0.55$ to 0.1 reduces the seasonal average of the specific surface area to a quarter of the original value of about $4000 \mathrm{~m}^{2} \mathrm{~m}^{-3}, d_{\text {ice }}$ increases from $0.8 \mathrm{~mm}$ to $1.7 \mathrm{~mm}$ and $d_{\text {pore }}$ decreases only slightly from $0.8 \mathrm{~mm}$ (which is comparable to the ice-cluster size at these depths) to $0.5 \mathrm{~mm}$.

To clarify the role of ice-cluster size in densification, the 16 firn-layer data for each $40 \mathrm{~cm}$ segment are subdivided into fine- and coarse-grained firn horizons. From the 16 layers the minimum and maximum values of $d_{\text {ice }}$ are determined. Thereafter, the mean of both is calculated and used as the threshold to discriminate fine- and coarse-grained layers. All layers with $d_{\text {ice }}$ less than the threshold value are assigned as fine-grained firn, others as coarse-grained firn. This procedure subdivides most of the segment data into groups of equal number with the exception of two datasets

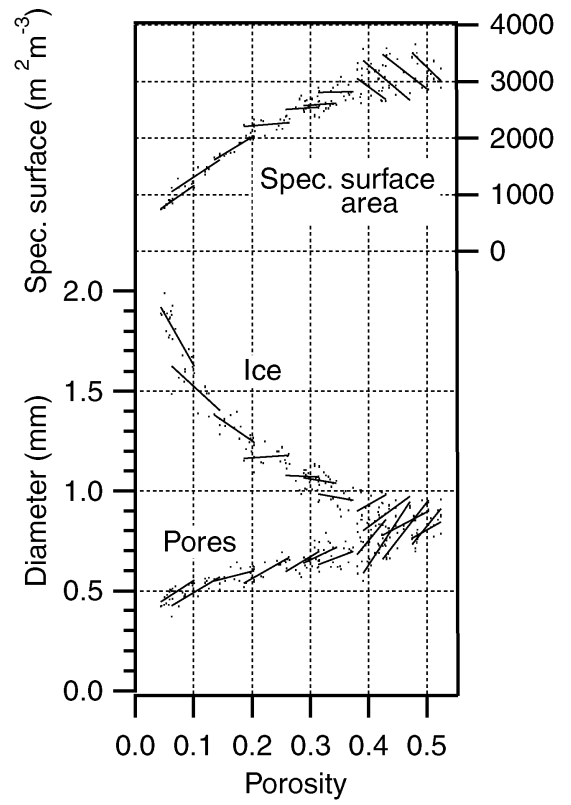

Fig. 6. Specific surface area $A_{\text {spec, }}$ mean ice cluster $d_{\text {ice }}$ and pore diameter $d_{\text {pore }}$ us porosity $n$ for all seasonal segments measured by XCT. Each of the segments is separately fitted on a linear regression curve.

from 28 and $32 \mathrm{~m}$ depth. Figure 7 displays the depth profiles of $d_{\text {ice }}, d_{\text {pore }}$ and $n$ separated into fine- and coarse-grained firn. Surprisingly, fine- and coarse-grained firn show a crossing-over at their porosity profiles. In the uppermost part of the profile down to $20 \mathrm{~m}$ (equal to $n=0.35$ ), coarsegrained firn is more porous than fine-grained firn. In the

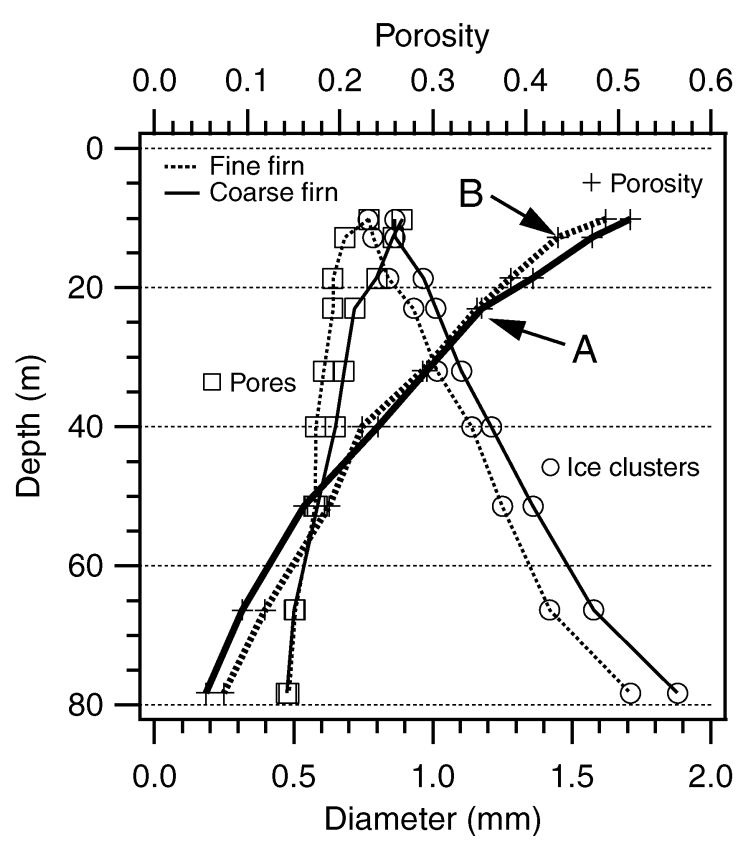

Fig. 7. Depth profiles of porosity (crosses), ice-cluster (circles) and pore (squares) diameter for fine- and coarsegrained firn. The data for fine-grained firn are connected with dotted lines. The data for coarse-grained firn are connected with solid lines. The arrows indicate the assumed positions of the critical porosities separating the initial and intermediate stage of densification for coarse-grained ( $A$ ) and fine-grained (B) firn. Both porosity profiles become congruent by shifting the curve of fine-grained firn such that point $B$ fits point $A$. 
depth range $20-40 \mathrm{~m}$ (corresponding to the range $0.35-0.2$ in porosity), coarse- and fine-grained firn reach equal porosity, whereas below $40 \mathrm{~m}(n<0.35)$ the coarse-grained firn is less porous. During the densification process, the pore diameters $d_{\text {pore }}$ of fine- and coarse-grained firn converge with depth and become approximately equal below $50 \mathrm{~m}$, whereas the ice-cluster diameters increase roughly linearly with depth and maintain differences of $0.2 \mathrm{~mm}$ between fine- and coarse-grained firn.

\section{DISGUSSION}

\section{Methodological aspects}

The firn-cube reconstructions generated by the XCT method allow estimates of mean ice-cluster and pore sizes over approximately 1000 elements (equal to the volume of 10 crystal or pore diameters in each direction) with a standard deviation of about $2.5 \mu \mathrm{m}$ taking into account the twofold spatial resolution of $80 \mu \mathrm{m}$ from the XCT device. However, due to the non-negligible width of the size distributions of up to $0.41 \mathrm{~mm}$, changes of the mean ice and pore sizes are only significant when the differences are larger than the confidence interval of a single value. The $95 \%$ confidence interval of the mean is given by $z \sigma_{\text {ice }} / \sqrt{m}$ with $z=1.96$. For maximum $\sigma_{\text {ice }}$ of $0.41 \mathrm{~mm}$ and 1000 elements $(m=1000)$ the confidence interval becomes $25 \mu \mathrm{m}$ which is approximately one-tenth of the measured seasonal variability in the firn horizons (Fig. 5). Therefore, the observed size changes within seasonal layers are significant and not only of stochastic origin.

By comparing the specific surfaces values, ice-cluster sizes and growth rates with estimates derived from 2-D cross-sections, we find a good agreement in magnitude. For example, Alley and others (1982) measured structural parameters on 2-D cross-sections of a $50 \mathrm{~m}$ long Antarctic firn core at Dome C. They obtained specific surface area values falling into the same range of $1000-4000 \mathrm{~m}^{2} \mathrm{~m}^{-3}$ as presented in this study. Gow (1975) observed that crystal crosssectional areas increase linearly with time in the isothermal regime of firn below $15 \mathrm{~m}$. For a Greenland location (Inge Lehmann) with a mean temperature of $T=-30^{\circ} \mathrm{C}$ he estimated a crystal growth rate of $6-7 \times 10^{-3} \mathrm{~mm}^{2} \mathrm{a}^{-1}$. To compare estimates of grain growth, the 3 -D ice clusters are reduced to their $2-\mathrm{D}$ projections given as $\pi d_{\text {ice }}^{2} / 4$. The depth is transformed to a time-scale by using the density profile and accumulation rate.

As is shown in Figure 8, the ice-cluster cross-sectional area also increases linearly with time except for the deeper part below $66 \mathrm{~m}$ (equal to $t>240$ years). The ice-cluster growth rates for fine- and coarse-grained firn are similar, at $5.35 \times 10^{-3}$ and $6.41 \times 10^{-3} \mathrm{~mm}^{2} \mathrm{a}^{-1}$ respectively. The rates correspond quite well with the crystal growth rates of 6 $7 \times 10^{-3} \mathrm{~mm}^{2} \mathrm{a}^{-1}$ obtained from 2-D cross-sections by Gow (1975). Measurements on thin sections of firn cubes already measured by XCT show that the mean crystal cross-sectional area estimated by different methods differs only within a range of $20 \%$. This implies that a spherical ice cluster describes a single grain rather than an aggregate of grains. In other words, the densification process generates no compacted volumes with spherical dimensions larger than a single grain at least for the upper $66 \mathrm{~m}$. Below $66 \mathrm{~m}$, porechannel bonds begin to close, the firn becomes impermeable and the firn-ice transition is reached. Here, the ice-cluster

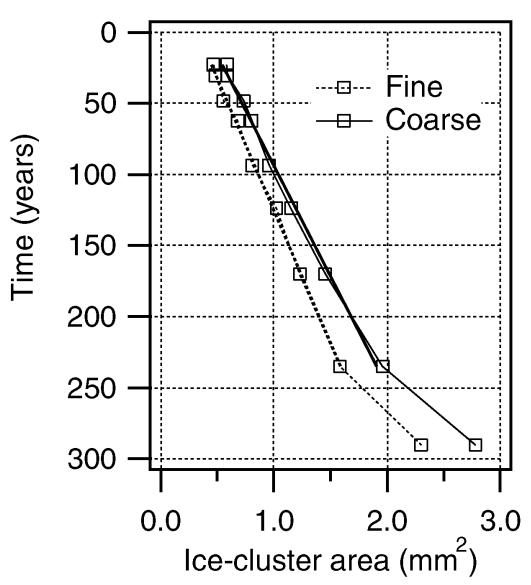

Fig. 8. Ice-cluster cross-sectional area as a function of time plotted for fine (dotted lines) and coarse firn (solid lines). The linear trends occur for the first 240 years of densification (which is equal to the first $66 \mathrm{~m}$ of the firn column).

size increases rapidly, possibly indicating that the ice cluster exceeds the volume of a single crystal. Although the reconstructed firn cubes exhibit the 3-D structure which illustrates the potential of the XCT method, the important information about the grain boundaries is not directly detectable. Here, a possible way to gain 3-D information about boundaries could be by numerical analysis of the ice-matrix data using specific split algorithms. However, a detailed discussion is beyond the scope of this paper.

\section{Firn densification}

The structural data of seasonal firn layers from the Greenland firn core presented above show that fine- and coarsegrained firn follow two different density-depth profiles as also shown by Alley and others (1982) from density profile analysis. The particle-size-dependent densification causes changes in the magnitude of seasonal density variations which are also measured by gamma absorption. The observed density-fluctuation minimum in the highly resolved density profile coincides with the porosity crossover point of fine- and coarse-grained firn (Figs 3 and 7). Following Equation (l) it is obvious that a porosity crossover is identical with a crossover for density. Therewith a simple two-layer approach subdivided into fine- and coarsegrained parts describes the main features of firn densification fairly well even though the classification is only done with the mean of the spherical ice-cluster size. A density crossing is also suggested by Gerland and others (1999) who measured the density and electrical conductivity in high resolution on a firn core retrieved at Berkner Island, Antarctica. They found an anticorrelation of electrical conductivity data to density at depths of $10 \mathrm{~m}$ which switched to a pronounced correlation at greater depths. This can only be explained by a change in either the conductivity or density relation within seasonal layers. This study tells us that the latter is the case.

A different approach to explaining density variations during densification was taken by Li and Zwally (2002). Being aware of the core profile measured by Gerland and others (1999), they formulated a one-dimensional timedependent numerical model to simulate the seasonal density variations in polar firn. Their model is based on a temperature-dependent formulation of firn densification. The 
simulated seasonal cycles, with highly compressed layers of snow deposited during spring to mid-summer and less compressed layers of snow deposited during later summer to autumn, show variations comparable to the observed data in the upper part of the firn column. In the model, the fluctuations decrease with depth without displaying a minimum at 20-30 m depth. Li and Zwally (2002) speculated that the fluctuation minimum might be caused by interannual changes of surface weather conditions. However, further measurements indicate that the distinct minimum is a common feature at almost all polar sites with relatively high accumulation rates of $100-200 \mathrm{~mm}$ w.e. $\mathrm{a}^{-1}$ and is unlikely to be a result of interannual changes (Gerland and others, 1999; Wilhelms, unpublished data; this study). Besides impurities, only differences in the firn structure can account for different densification rates. Notably fine- and coarsegrained layers densify at different rates even after both layers have reached the same density (at the point of crossing). The density crossover implies that formerly dense layers in the seasonal density signal are not of the same origin as dense layers in the deeper part of the firn column.

The two porosity-depth profiles for fine- and coarsegrained firn are similar in shape. A shift along the porosity and depth scales would bring both curves into congruence. An exclusive shift along the depth axis means that fine- and coarse-grained firn densify in the same manner but reach the same porosity under different pressure and after different periods of sintering. An exclusive shift along the porosity axis results in different critical densities for the dominant densification mechanism. Following this interpretation, it turns out that for fine-grained firn the transition from the first to the second stage of densification takes place at a critical density of $0.52 \mathrm{~g} \mathrm{~cm}^{-3}$ (relative density $=0.57$, porosity $n=0.43$ ) under an overburden snow pressure load of $0.49 \times 10^{5} \mathrm{~Pa}$ after a densification time of 30 years, whereas for coarse-grained firn the transition is reached at a critical density of about $0.60 \mathrm{~g} \mathrm{~cm}^{-3}$ (relative density $=0.65$, porosity $n=0.35$ ) under an enhanced snow pressure load of $1.0 \times 10^{5} \mathrm{~Pa}$ and after a longer densification time of about 62 years. The critical density of coarse-grained firn is approximately equal to the density of an ensemble of random packed spheres (relative density $=0.637$; German, 1989). Different critical densities lead to a crossing of the porositydepth profiles of fine- and coarse-grained firn because each densification mechanism densifies the firn at different rates. In the porosity-depth profiles, the second critical density originally suggested by Ebinuma and Maeno (1987) at $0.730 \mathrm{~g} \mathrm{~cm}^{-3}$ is identifiable as a similar shift between finegrained firn with a critical density of $0.72 \mathrm{~g} \mathrm{~cm}^{-3}$ (relative density $=0.78$, porosity $n=0.22$ ) and coarse-grained firn with a critical density of $0.77 \mathrm{~g} \mathrm{~cm}^{-3}$ (relative density = 0.84 , porosity $n=0.16$ ). The congruence in the porositydepth profiles indicates that the densification rates for fineand coarse-grained firn are quite similar within the sintering stages. However, the critical densities are different, as are the time and pressure conditions for reaching the different sintering stages. It is interesting to note that the pore sizes at the critical densities are similar for fine- and coarse-grained firn. But what causes the differences in the critical densities?

To explain different critical densities, the cluster size must be linked to other structural parameters which directly affect the densification mechanism, for example to the number of contacts between particles (coordination number), to the area fraction which is involved in the grain-to-grain interfaces or to a shape factor of the grains (Alley and others, 1982; Alley, 1987b). For all that, the boundaries of a single grain have to be known. Unfortunately, grain boundaries are not directly detectable by the XCT method. Considering the pore space during densification, it is surprising that the pores are compacted independently of the grainsize to the same spherically equivalent dimensions of about $0.5 \mathrm{~mm}$ in diameter before close-off (Fig. 7). This emphasizes that the pore dimensions might play an important role in determining the transitions to different densification stages.

\section{GONGLUSIONS}

The densification process of polar firn at sites with relatively high accumulation rates of $100-200 \mathrm{~mm}$ w.e. $\mathrm{a}^{-1}$ and moderate mean temperatures of about $-30^{\circ} \mathrm{C}$ is accompanied by seasonal density variations with a local minimum in the density range of $0.55-0.65 \mathrm{~g} \mathrm{~cm}^{-3}$ or $20-30 \mathrm{~m}$ respectively. In order to explain the density variations and their minimum, the structural properties are investigated by applying a new method of XCTon polar firn. The XCT method was validated by independent density measurements using gamma absorption. A spatial resolution of $40 \mu \mathrm{m}$ and a cube size of $12 \mathrm{~mm}$ length allow for estimation of significant changes in the mean values of the 3-D ice cluster and pore-size distributions in the order of $25 \mu \mathrm{m}$ which is sufficient to detect changes within seasonal layers.

The data of a Greenland firn core presented above show that the seasonal density variations can be attributed to two firn layers defined as fine- and coarse-grained firn by means of the ice-cluster size with different densification rates. The porosity-depth profiles of fine- and coarse-grained firn display a crossover point in the range where the seasonal density variations reach their local minimum. Hereafter, the minimum is caused by the cluster-size-dependent densification rates of two different types of firn. To explain the different densification profiles it is speculated that in fine- and coarse-grained firn the dominating densification mechanism acts over different density regimes. For the firn-ice transition the regime shift implies that the isolation of air bubbles would occur first in fine-grained firn layers, followed by isolation in coarse-grained layers in the deeper part of the firn column. On the other hand, if the critical density of the firn-ice transition did not depend on microstructure and cluster size, air bubbles would be isolated in the dense coarse-grained layers first, followed by isolation in the fine-grained layers in the deeper part. However, in both cases the depth of the firn-ice transition differs with cluster size. In the former case the development of finegrained layers is crucial for the formation of bubbles, but in the latter case the development of coarse-grained layers is crucial. Hereafter, different atmospheric boundary conditions favoring either coarse- or fine-grained layers at the snow surface could influence the depth of the firn-ice transition. A detailed investigation of the firn-ice transition by the XCT method described here will be part of future work.

\section{ACKNOWLEDGEMENTS}

We would like to thank the field team of the Alfred Wegener Institute-North-Greenland traverse in 1995. We are also grateful to E. Burkhardt and K. Tietze for accurate work in 
the cold room and to H.-J. Vogel for numerical support. We also wish to thank M. Lange, A. Gow and R. Alley for helpful comments and for critically reviewing the manuscript.

\section{REFERENCES}

Alley, R. B. 1987a. Firn densification by grain-boundary sliding: a first model. F. Phys. (Paris), 48, Colloq. C1, 249-254.

Alley, R. B. 1987b. Texture of polar firn for remote sensing. Ann. Glaciol., 9, $1-4$.

Alley, R. B., J. F. Bolzan and I. M. Whillans. 1982. Polar firn densification and grain growth. Ann. Glaciol., 3, 7-11.

Anderson, D. L. and C. S. Benson. 1963. The densification and diagenesis of snow. In Kingery, W. D., ed. Ice and snow: properties, processes, and applications. Cambridge, MA, MIT Press, 391-411.

Arnaud, L., M. Gay, J.-M. Barnola and P. Duval. 1998. Imaging of firn and bubbly ice in coaxial reflected light: a new technique for the characterization of these porous media. F. Glaciol., 44(147), 326-332.

Arnaud, L., J. M. Barnola and P. Duval. 2000. Physical modeling of the densification of snow/firn and ice in the upper part of polar ice sheets. In Hondoh, T., ed. Physics of ice core records. Sapporo, Hokkaido University Press, 285-305.

Arzt, E. 1982. The influence of an increasing particle coordination on the densification of spherical powders. Acta Metall., 30, 1883-1890.

Ebinuma, T. and N. Maeno. 1987. Particle rearrangement and dislocation creep in a snow-densification process. F. Phys. (Paris), 48, Colloq. Cl, 263-268.

Freitag, J., U. Dobrindt andJ. Kipfstuhl. 2002. A new method for predicting transport properties of polar firn with respect to gases on the pore-space scale. Ann. Glaciol., 35, 538-544.

Gerland, S., H. Oerter, J. Kipfstuhl, F. Wilhelms, H. Miller and W. D. Miners. 1999. Density log of a $181 \mathrm{~m}$ long ice core from Berkner Island, Antarctica. Ann. Glaciol., 29, 215-219.
German, R. M. 1989. Particle packing characteristics. Princeton, NJ, Metal Powder Industries Federation.

German, R. M. 1996. Sintering theory and practice. New York, etc., John Wiley and Sons, Inc.

Gow, A. J. 1968. Deep core studies of the accumulation and densification of snow at Byrd Station and Little America V, Antarctica. CRREL Res. Rep., 197(45).

Gow, A.J. 1975. Time-temperature dependence of sintering in perennial isothermal snowpacks. International Association of Hydrological Sciences Publication 114 (Symposium at Grindelwald 1974 - Snow Mechanics), 25-41.

Herron, M. M. and C. C. Langway, Jr. 1980. Firn densification: an empirical model. 7. Glaciol., 25(93), 373-385.

Li Jun and H. J. Zwally. 2002. Modeled seasonal variations of firn density induced by steady-state surface air-temperature cycle. Ann. Glaciol., 34, 299-302.

Lundy, C. C., M. Q. Edens and R. L. Brown. 2002. Measurement of snow density and microstructure using computed tomography. 7. Glaciol., 48 (161), 312-316.

Maeno, N. and T. Ebinuma. 1983. Pressure sintering of ice and its implication to the densification of snow at polar glaciers and ice sheets. F. Phys. Chem., 87(21), 4103-4110.

Schwager, M. 2000. Eisbohrkernuntersuchungen zür räumlichen und zeitlichen Variabilität von Temperatur und Niederschlagsrate im Spätholozän in Nordgrönland. Ber. Polarforsch. 362.

Serra, J. 1982. Image analysis and mathematical morphology. London, Academic Press.

Stauffer, B., J. Schwander and H. Oeschger. 1985. Enclosure of air during metamorphosis of dry firn to ice. Ann. Glaciol., 6, 108-112.

Vogel, H. J. 1997. Morphological determination of pore connectivity as a function of pore size using serial sections. Soil Science, 48, 365-377.

Wilhelms, F. 1996. Leitfähigkeits- und Dichtemessung an Eisbohrkernen. Ber. Polarforsch. 191.

Wilkinson, D. S. 1988. A pressure-sintering model for the densification of polar firn and glacier ice. f. Glaciol., 34(116), 40-45. 